\title{
The Effects of Notches on the Fatigue Strength of Steel Structures
}

\author{
Pavol Juhas ${ }^{1, *}$ \\ ${ }^{1}$ Institute of Technology and Business in České Budějovice, Department of Civil Engineering, \\ Okružní 517/10, 37001 České Budějovice Czech Republic
}

\begin{abstract}
The paper informs about the research devoted to load-carrying capacity, fatigue strength and life-time of welded steel structures. The experimental programme comprises fatigue tests of constructional steel S380 (QStE $380 \mathrm{TM}$ ). In the first stage 35 specimens were tested: 9 without any weld connection, 14 with transverse milled butt weld and 12 with transverse rough butt weld. The applied loading in this stage was harmonic with constant stress range. All tests ended by fatigue failure. The second part of the research comprised the tests with block simulated loading with variable stress range. The third part applied continuous recording of stresses and strains in critical sections, that gave information about the local failure development in time. Data sets have allowed to define fatigue properties of investigated steel and degradation effects of used welds including the initiation time of remarkable changes in stressstrain stage expressed through the total kinetic energy. The degradation effects of welds on fatigue strength of structural steels were confirmed, especially it was the case of rough welds - without additional milling. Additionally, the differences in the fatigue curves inclinations were indicated that can depend on the level of fatigue strength. The applied approach gives an opportunity to analyse the effects of actual loading process and improve the methodology of judgement of fatigue strength and life-time of steel elements. Reasonable fatigue properties of this steel suggest it for using also in severe technology structures.
\end{abstract}

\section{Introduction}

Steel structural elements create carrying systems of many bridges and industrial structures and are frequently subjected to repeated loading. Generally, it is accepted that their resistance capacity could not be fully utilised because of unfavourable fatigue effects. However, when dealing with dynamic response of any structure, the effects of changes both in stiffness and damping should be taken into account. The consequence is the mixture of favourable and unfavourable effects. The stress-strain state of structure depends on geometrical and material properties and on the level and mode of loading. Thus, the stressstrain relations are non-linear and the response of structure is influenced by the interaction of the behaviour of basic material, type of connections, their quality and workmanship.

\footnotetext{
*Corresponding author: 15364@mail.vstecb.cz
} 
The crucial point is the resistance of connections while expecting the concentration of strains and stresses in the most vulnerable points. The paper presents the analysis of experimental results obtained when dealing with the variable loading tests of sample rods with butt welds. The overall objective is to provide a better insight into the actual behaviour of steel structures under extreme variable loading including the accidental one [1], [2], [3].

\section{Experimental programme}

The experimental programme comprised fatigue tests of constructional steel S380 (QStE $380 \mathrm{TM})$. Three groups of specimens were tested: the original standard specimens, the specimens with transverse butt weld connection which was additional milled and the specimens with transverse rough butt weld connection. Part of the experimental programme had run using harmonic loading with constant amplitude and results are described in details elsewhere [4], [5], [6]. Another group of specimens was subjected to block fatigue tests with variable amplitude of loading based on strain records on actual structures. Every block of loading consisted of 7 steps, each of 10 cycles of frequency $1 \mathrm{~Hz}$ for the largest amplitude step and $6 \mathrm{~Hz}$ for remaining 6 smaller amplitude steps. Used loading corresponds to decreasing mean value (216-154-139-137-132-33-26 MPa) and the stress range Ds (42770-169-204-53-18-18 MPa). Original dimensions of tested samples are in Fig. 1. In order to understand the development of strains and stresses in the most vulnerable sections of the rod samples, the setup of test comprised the miniature folia strain gauges and the extensometer, as can be seen in Fig. 2. The continuous time histories of 8 channels data acquisition system used $100 \mathrm{~Hz}$ sampling frequency while recording: reference signal (ch. 1), applied force (ch. 2), total relative displacement (ch. 3), extension at the base of $23 \mathrm{~mm}$ including welded part (ch. 4), strains at nodal sections (chs. 5,6,7,8). In the case of rough butt weld the strain gauges were placed on the lateral sides of the tested rod, in case of milled butt weld the strain gauges were placed on front side of the tested rod in four transition sections, see Fig. 2.

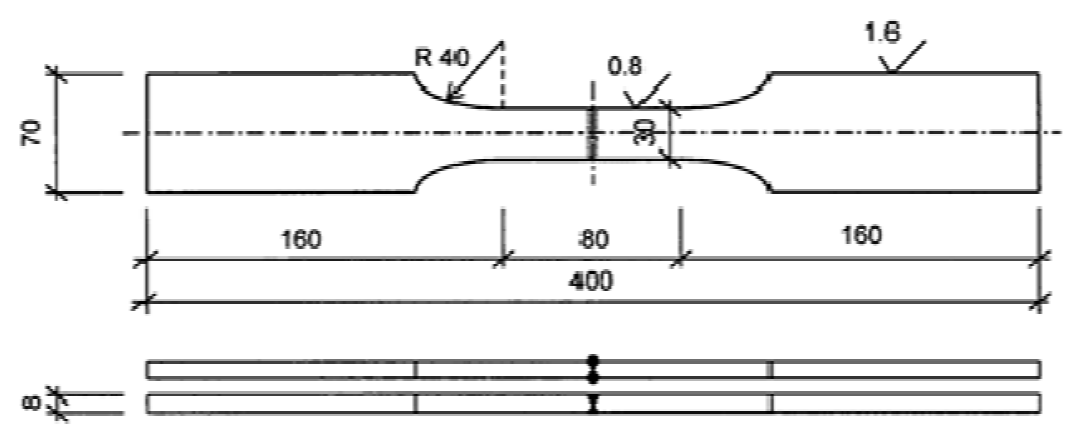

Fig. 1. Dimensions of tested rod samples. 

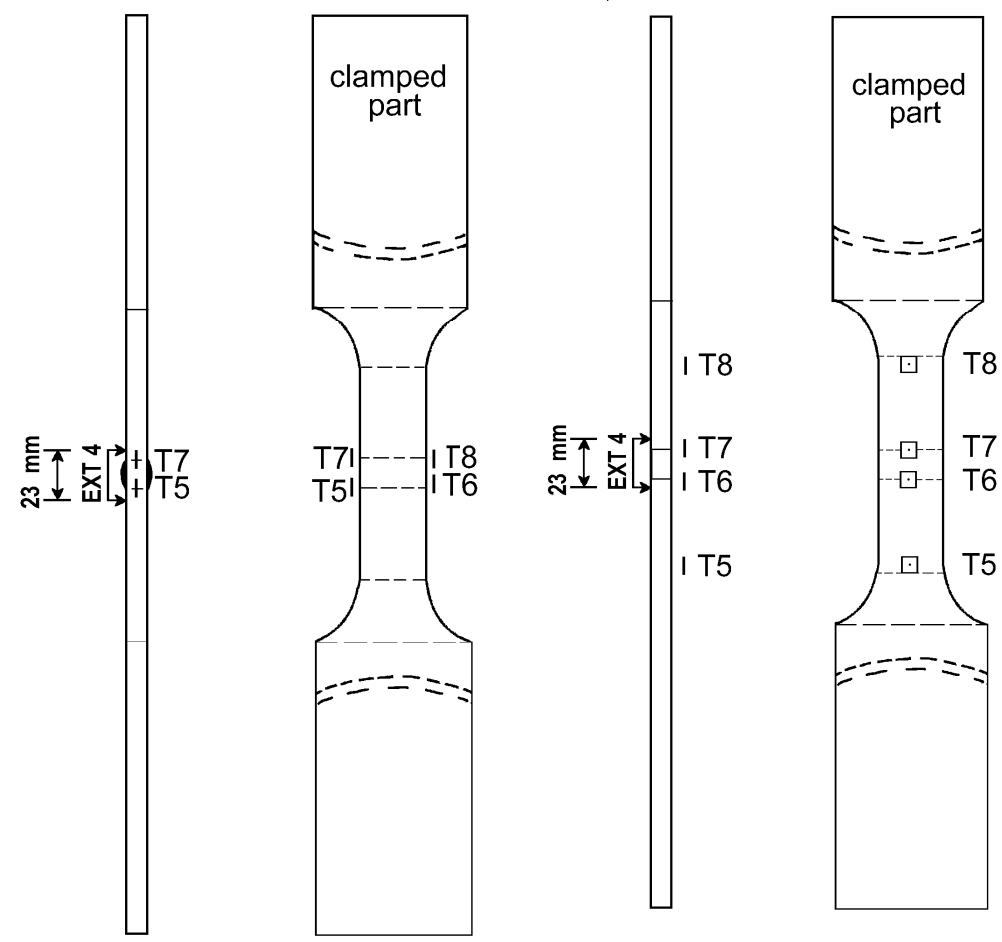

Fig. 2. The setup of variable amplitude fatigue test on the rod samples (with rough butt weld on the left, with milled butt weld on the right).

\section{Test results}

The general observation of time histories enabled to receive detailed information about the stress-strain development in time and in space. Redistribution of strains inside of sample rod is dependent on the quality of the workmanship and the stress concentration near the welded sections. To this end, every tested rod with rough butt weld exhibited the final failure at the transition section between the rough butt weld and the original rod section. The tested rods with milled butt weld exhibited two types of a failure. The failure (broken rod) appeared either at the transition section between central original rod part and the curved part or at the transition section between the milled butt weld and the original rod section.

Time histories of investigated quantities indicated important stages in strain increases. First of all, at the test beginning, the largest strain increase appeared in the transition sections, either below or above the weld connection. The tendency of the increasing strains was successively passing into the stabilized constant stage that remained until the next nearly negligible changes appeared in the records. Afterwards, the strain increase reached the stage that can be called yielding. The process continued up to final failure - broken rod, as can be seen in Fig. 3 and Fig. 4. Table 1 gives number of blocks reached for these stages.

It should be understood that in some cases of milled butt welds, the failure appeared in another part of the tested rod. Then, the beginning of yielding was not such sharply evident as it was in cases of samples 5/4, 5, 12 and 17. However, the first indication of yielding is an important issue for taking an appropriate measure as to save or improve the structure integrity [4], [5], [6]. 
Table 1. Reached Number of Blocks during the Variable Amplitude Fatigue Tests

\begin{tabular}{|c|c|c|c|c|}
\hline \multirow[b]{2}{*}{ Type of butt weld } & \multicolumn{4}{|c|}{ Number of loading blocks } \\
\hline & \begin{tabular}{|l|} 
The first \\
strain change \\
Nb1
\end{tabular} & $\begin{array}{l}\text { Start of the } \\
\text { yielding } N b y\end{array}$ & $\begin{array}{l}\text { Failure - } \\
\text { broken rod } \\
N \text { bf }\end{array}$ & $\begin{array}{l}\text { Ratio } \\
\text { Nby/Nbf }\end{array}$ \\
\hline $1-$ milled $-\mathrm{a}$ & 1089 & 2179 & 2339 & 0.932 \\
\hline $2-$ milled $-\mathrm{a}$ & 53 & 305 & 419 & 0.728 \\
\hline $3-$ milled $-\mathrm{a}$ & - & 4109 & 4662 & 0.881 \\
\hline $5 / 4-$ milled $-\mathrm{w}$ & 1448 & 3059 & 3909 & 0.783 \\
\hline $5-$ rough $-w$ & - & 2271 & 2749 & 0.826 \\
\hline $12-$ rough $-\mathrm{w}$ & 2039 & 2279 & 2859 & 0.797 \\
\hline $17-$ rough $-\mathrm{w}$ & - & 2358 & 2738 & 0.862 \\
\hline
\end{tabular}

Note: $\mathrm{a}$ - failure aside, near the rounded part; $\mathrm{w}-$ failure at the butt weld

When dealing with accidental loading, the passage of strains and stresses into non-linear range is very likely. In relation to the time history of loading, the frequency and time needed for keeping the structure behind the yield point suggest the evaluation of cumulative stresses and strains up to the structure failure. In small elastic-plastic deformation theory it is presumed that after yielding the constitutive equations are controlled by strain and stress velocities. Thus, the quantities related to velocity time histories help with the indication of local adverse changes in time.
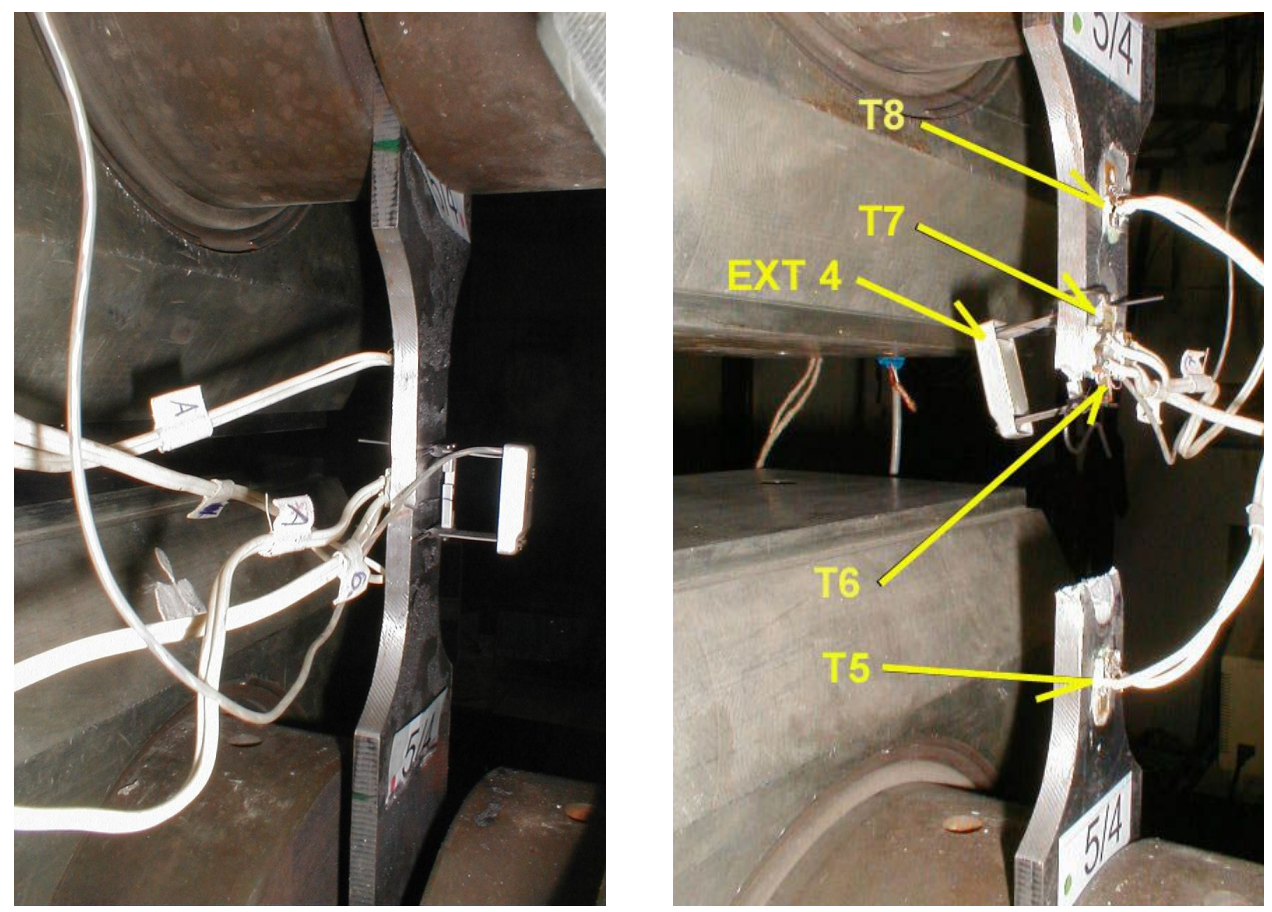

Fig. 3. The view of tested rod 5/4 with milled butt weld (on the left - initiation of crack; on the right - at the end of fatigue test). 

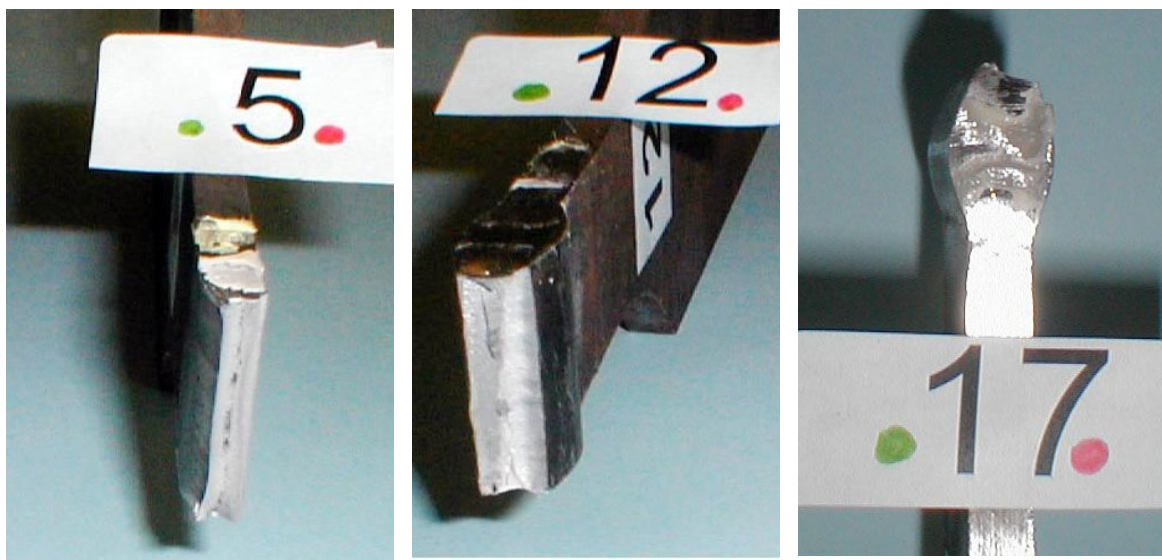

Fig. 4. The appearance of broken rods 5, 12 a 17 with rough butt welds after fatigue failure.

The final stage of test in the case of rod 5/4 is shown on Fig. 5. It is described by time histories of measured quantities until the failure. The strains and the deflection exhibited remarkable changes in and growing up their values.
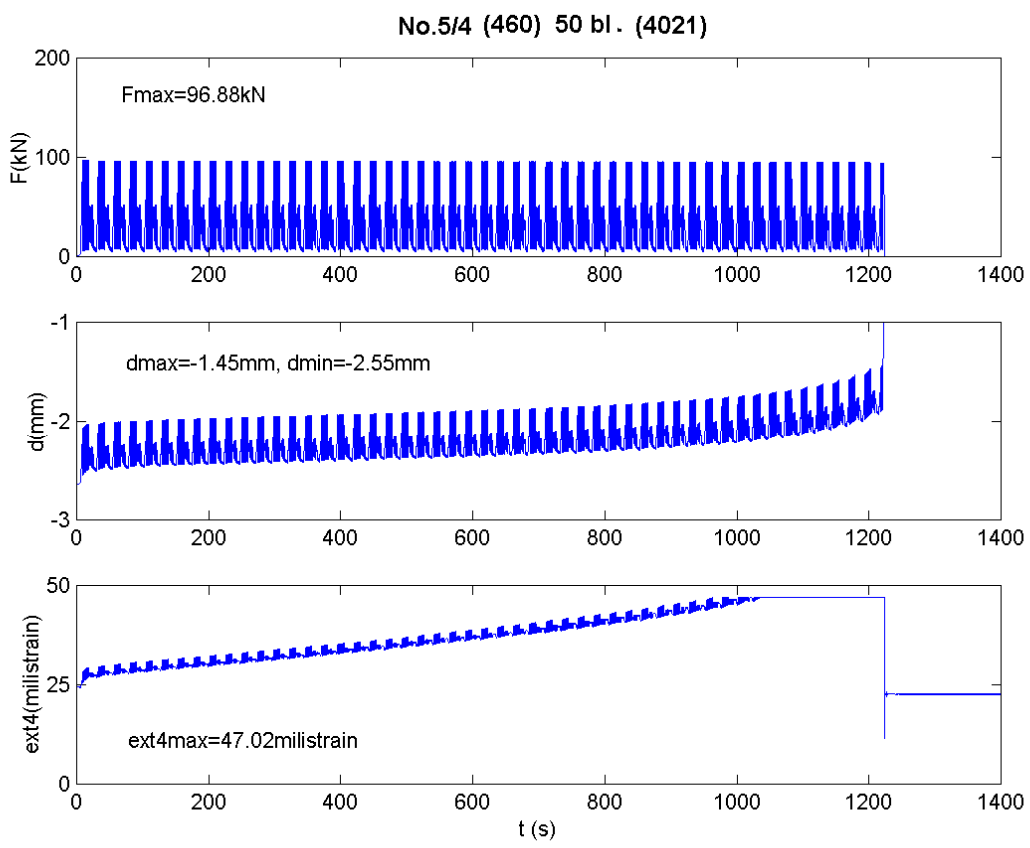

Fig. 5. Time histories of the force $F$, deflection between tension grips $d$ and strain ext4 at the test end of sample rod 5/4, including the failure stage "

Especially in the case of accidental loading, it is frequently observed the transition of strains and stresses into non-linear region. Then, the evaluation of cumulative stresses and strains until the failure can be applied, taking into account the time history of loading, its frequency content and the duration of time, when the tested rod was subjected to stresses above the yield stress. In agreement with theory of small elastic-plastic deformations it is assumed, that during plastification process the state equations are controlled by velocities of 
strains and stresses. Thus, the velocities of respective quantities can be used for indication of initiation and development of adverse local strains and stresses in time.

Results of fatigue tests with constant stress range $\Delta \sigma$ are in Table 2. All tests (with two exceptions) finished by fatigue failure of tested rods. If the failure did not appear before 10 millions of cycles, the test was interrupted and the stress range $\Delta \sigma$ was increased for reaching the reasonable duration of the test. The evaluation considers total number of cycles $N$ and modified stress range $\Delta \sigma=\left(\Delta \sigma_{1} N_{1}+\Delta \sigma_{2} N_{2}\right) / N$, where $\Delta \sigma_{\mathrm{i}}$ a $N_{\mathrm{i}}$ are corresponding stress ranges and corresponding numbers of cycles, respectively.

Table 2. Results of Basic Fatigue Tests with Constant Amplitude of Loading.

\begin{tabular}{|c|c|c|c|c|c|c|}
\hline \multirow{2}{*}{$\begin{array}{l}\text { Tested } \\
\text { rod }\end{array}$} & \multicolumn{2}{|c|}{ Dimensions (mm) } & \multicolumn{2}{|c|}{ Stress range } & \multirow{2}{*}{$\begin{array}{c}\text { Number of } \\
\text { cycles } \mathrm{N} \\
\text { (thousands) }\end{array}$} & \multirow{2}{*}{$\begin{array}{l}\text { Mode } \\
\text { of } \\
\text { failure }\end{array}$} \\
\hline & $\mathbf{t}$ & $\mathbf{b}$ & $\sigma_{\mathrm{D}} \leftrightarrow \sigma_{\mathrm{H}}$ & $\Delta \sigma$ (MPa) & & \\
\hline NOW 1 & 8.06 & 30.10 & $(0.20 \leftrightarrow 0.95) \sigma_{y}$ & 310.5 & 212.5 & 11 \\
\hline NOW 2 & 7.88 & 29.82 & $(0.20 \leftrightarrow 0.95) \sigma_{y}$ & 310.5 & 249.3 & 11 \\
\hline NOW 3 & 8.02 & 30.10 & $(0.20 \leftrightarrow 0.95) \sigma_{\mathrm{y}}$ & 310.5 & 214.9 & 11 \\
\hline NOW 4 & 7.96 & 30.46 & $(0.20 \leftrightarrow 0.80) \sigma_{y}$ & 248.4 & 2125.4 & 11 \\
\hline NOW 5 & 8.00 & 30.34 & $(0.20 \leftrightarrow 0.80) \sigma_{y}$ & 248.4 & 1052.0 & 11 \\
\hline NOW 6 & 8.10 & 30.60 & $(0.20 \leftrightarrow 0.80) \sigma_{y}$ & 248.4 & - & 4 \\
\hline NOW 7 & 8.10 & 30.20 & $\begin{array}{l}(0.20 \leftrightarrow 0.65) \sigma_{y} \\
(0.20 \leftrightarrow 0.80) \sigma_{y}\end{array}$ & $190.8^{1)}$ & $\begin{array}{r}10000.0 \\
774.1 \\
\end{array}$ & 12 \\
\hline NOW 8 & 8.00 & 30.00 & $\begin{array}{l}(0.20 \leftrightarrow 0.65) \sigma_{y} \\
(0.20 \leftrightarrow 0.80) \sigma_{y}\end{array}$ & $200.9^{1)}$ & $\begin{array}{r}10000.0 \\
3060.0\end{array}$ & $12^{2)}$ \\
\hline NOW 9 & 7.90 & 29.70 & $\begin{array}{l}(0.20 \leftrightarrow 0.65) \sigma_{y} \\
(0.20 \leftrightarrow 0.80) \sigma_{y}\end{array}$ & $213.9^{1)}$ & $\begin{array}{r}10000.0 \\
7984.4 \\
\end{array}$ & $12^{2)}$ \\
\hline BWM 1 & 8.10 & 30.20 & $(0.20 \leftrightarrow 0.95) \sigma_{\mathrm{y}}$ & 310.5 & 185.5 & 21 \\
\hline BWM 2 & 7.84 & 30.24 & $(0.20 \leftrightarrow 0.95) \sigma_{\mathrm{y}}$ & 310.5 & 415.3 & 22 \\
\hline BWM 3 & 8.00 & 30.02 & $(0.20 \leftrightarrow 0.95) \sigma_{\mathrm{y}}$ & 310.5 & 141.2 & 21 \\
\hline BWM 4 & 7.86 & 30.42 & $(0.20 \leftrightarrow 0.80) \sigma_{\mathrm{y}}$ & 248.4 & 221.6 & 2 \\
\hline BWM 5 & 7.90 & 30.00 & $(0.20 \leftrightarrow 0.80) \sigma_{\mathrm{y}}$ & 248.4 & 1246.8 & 11 \\
\hline BWM 6 & 7.92 & 30.20 & $(0.20 \leftrightarrow 0.80) \sigma_{y}$ & 248.4 & 197.9 & 22 \\
\hline BWM 7 & 7.70 & 30.38 & $(0.20 \leftrightarrow 0.80) \sigma_{y}$ & 248.4 & 469.2 & 22 \\
\hline BWM 8 & 8.00 & 30.50 & $\begin{array}{c}(0.20 \leftrightarrow 0.725) \sigma_{y} \\
(0.20 \leftrightarrow 0.80) \sigma_{y}\end{array}$ & 230.8 & $\begin{array}{r}10000.0 \\
7679.4 \\
\end{array}$ & $22^{2)}$ \\
\hline BWM 9 & 8.00 & 30.30 & $\begin{array}{c}(0.20 \leftrightarrow 0.725) \sigma_{y} \\
(0.20 \leftrightarrow 0.80) \sigma_{y}\end{array}$ & $219.6^{1)}$ & $\begin{array}{r}10000.0 \\
788.2 \\
\end{array}$ & 22 \\
\hline BWM 10 & 8.10 & 30.20 & $\begin{array}{c}(0.20 \leftrightarrow 0.725) \sigma_{y} \\
(0.20 \leftrightarrow 0.80) \sigma_{y}\end{array}$ & 231.0 & $\begin{array}{r}10000.0 \\
7878.2 \\
\end{array}$ & $22^{2)}$ \\
\hline BWM 11 & 8.30 & 30.45 & $\begin{array}{l}(0.20 \leftrightarrow 0.65) \sigma_{y} \\
(0.20 \leftrightarrow 0.80) \sigma_{y}\end{array}$ & $187.2^{1)}$ & $\begin{array}{r}10000.0 \\
146.4 \\
\end{array}$ & 22 \\
\hline BWM 12 & 7.85 & 30.40 & $(0.20 \leftrightarrow 0.65) \sigma_{y}$ & 186.3 & 701.3 & 21 \\
\hline BWM 13 & 7.70 & 30.20 & $\begin{array}{l}(0.20 \leftrightarrow 0.65) \sigma_{y} \\
(0.20 \leftrightarrow 0.80) \sigma_{y}\end{array}$ & 194.6 & $\begin{array}{r}10000.0 \\
1552.1 \\
\end{array}$ & $12^{2)}$ \\
\hline BWM 14 & 7.80 & 30.50 & $(0.20 \leftrightarrow 0.65) \sigma_{y}$ & 186.3 & 7500.0 & 3 \\
\hline
\end{tabular}




\begin{tabular}{|l||c|c|c|c|c|c|}
\hline \multirow{2}{*}{$\begin{array}{c}\text { Tested } \\
\text { rod }\end{array}$} & \multicolumn{1}{||}{ Dimensions (mm) } & \multicolumn{2}{c|}{ Stress range } & $\begin{array}{c}\text { Number of } \\
\text { cycles N } \\
\text { (thousands) }\end{array}$ & $\begin{array}{c}\text { Mode } \\
\text { of } \\
\text { failure }\end{array}$ \\
\cline { 2 - 5 } & $\mathbf{t}$ & $\mathbf{b}$ & $\sigma_{\mathrm{D}} \leftrightarrow \sigma_{\mathrm{H}}$ & $\Delta \sigma(\mathbf{M P a})$ & 25.8 & 22 \\
\hline BWR 1 & 8.20 & 29.80 & $(0.20 \leftrightarrow 0.95) \sigma_{\mathrm{y}}$ & 310.5 & - & 4 \\
\hline BWR 2 & 7.90 & 29.90 & $(0.20 \leftrightarrow 0.95) \sigma_{\mathrm{y}}$ & 310.5 & 38.4 & 22 \\
\hline BWR 3 & 7.95 & 30.20 & $(0.20 \leftrightarrow 0.95) \sigma_{\mathrm{y}}$ & 310.5 & 91.9 & 22 \\
\hline BWR 4 & 8.04 & 30.10 & $(0.20 \leftrightarrow 0.80) \sigma_{\mathrm{y}}$ & 248.4 & 50.8 & 22 \\
\hline BWR 5 & 7.80 & 29.90 & $(0.20 \leftrightarrow 0.80) \sigma_{\mathrm{y}}$ & 248.4 & 89.3 & 22 \\
\hline BWR 6 & 7.90 & 29.92 & $(0.20 \leftrightarrow 0.80) \sigma_{\mathrm{y}}$ & 248.4 & 291.0 & 21 \\
\hline BWR 7 & 8.01 & 30.20 & $(0.20 \leftrightarrow 0.65) \sigma_{\mathrm{y}}$ & 186.3 & 716.4 & 21 \\
\hline BWR 8 & 7.95 & 30.10 & $(0.20 \leftrightarrow 0.65) \sigma_{\mathrm{y}}$ & 186.3 & 173.5 & 21 \\
\hline BWR 9 & 7.90 & 30.03 & $(0.20 \leftrightarrow 0.65) \sigma_{\mathrm{y}}$ & 186.3 & 2773.4 & 21 \\
\hline BWR 10 & 8.10 & 30.15 & $(0.20 \leftrightarrow 0.50) \sigma_{\mathrm{y}}$ & 124.2 & 734.5 & 21 \\
\hline BWR 11 & 8.00 & 29.90 & $(0.20 \leftrightarrow 0.50) \sigma_{\mathrm{y}}$ & 124.2 & 10000.0 & 21 \\
\hline BWR 12 & 7.85 & 30.10 & $(0.20 \leftrightarrow 0.50) \sigma_{\mathrm{y}}$ & 128.1 & 1000 \\
\hline
\end{tabular}

Notes: ${ }^{1)}$ Modified stress range $\Delta \sigma,{ }^{2}$ Failure aside of basic - investigated part of the tested $\operatorname{rod}$

The mode of failure is another very important evaluation characteristic. It is presented in the last column of Table 2 for individual tested rods as follows: 1 - failure in basic material; 2 - failure at the weld; 3 - unfinished test; 4 - incorrect test; 11 - failure in basic material, the crack initiation at the edge of tested rod; 12 - failure in basic material, the crack initiation at the surface of tested rod; 21 - failure at the weld, the crack initiation at the edge of tested rod; 22 - failure at the weld, the crack initiation at the surface of tested rod. The characteristic fatigue cracks are in Fig. 6.
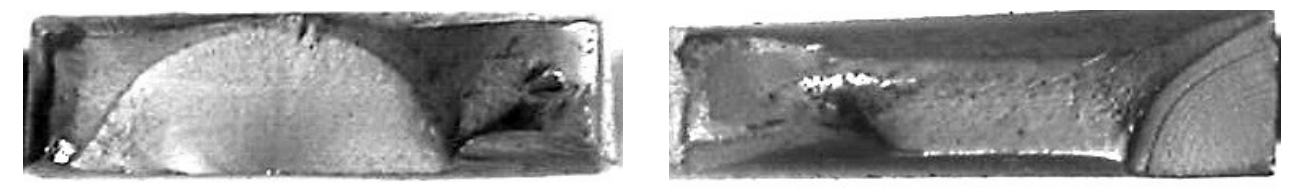

Fig. 6. The Characteristic Transverse Fatigue Cracks in Tested Rods

\section{Conclusions}

The presented test results and their evaluation confirm good fatigue properties and reasonable ductility of analysed structural steel S380 (KODUR E 380, QStE 380TM). Its fatigue strength fully complies the standard demands on important steel structures and equipment. The surface elaboration and the quality of welding have an important influence on mechanical properties of butt weld connections. In the case of milled butt welds, the fatigue strength of steel has decreased according to Standard classification of such detail. It should be said that some tested rods suffered damage at another place. Such tests were evaluated as those of rods without any weld. In the case of rough butt welds, the fatigue strength of steel has significantly decreased in comparison with Standard classification of such detail. 
Obtained experimental dependences $\Delta \sigma-\mathrm{N}$ and corresponding Standard fatigue curves could be used also for the evaluation of results obtained by fatigue tests with variable block loading. Very good toughness of basic material and weld connection allows the effective use of this steel in the structures subjected to the accidental actions with allowance for short term stresses beyond the yield stress provided that the used material shows appropriate ductility in exposed sections. The results of realised fatigue tests have confirmed correctness and importance of fatigue curves limitation, which is applied also in Slovak National Annex to EN 1993-1-9: 2005 [7], [8].

\section{References}

1. M. Bíly, V.S. Ivanova, V.F. Terentev, The Strength of Components and Materials under Variable Loading (VEDA, Bratislava, 1976)

2. P. Juhás, Building Res. Journ., 39/11, 599-618 (1991)

3. P. Juhás, Proc. Extending of Lifespan of Structures, IABSE Symposium, 1085-1090 (San Francisco, 1995)

4. P. Juhás, E. Juhásová, O. Roth, Acta Metallurgica Slovaca, 7/1, 44-54 (2001)

5. P. Juhás, E. Juhásová, O. Roth, Welding, 50/3-4, 13-17 (2001)

6. P. Juhás, O. Roth, Inžinierske stavby, 50, 20-24. (2002)

7. K. Kálna, Welding, 54/11-12, 304-311 (2005)

8. EN 1993-1-9: 2005 “Design of Steel Structures, Part 1.9: Fatigue," (CEN, Brussels, 2005) 